\title{
High-Level Expression of Alkaline Phosphatase by Adeno-Associated Virus Vector Ameliorates Pathological Bone Structure in a Hypophosphatasia Mouse Model
}

\author{
Aki Nakamura-Takahashi ${ }^{1,2} \cdot$ Toshiki Tanase $^{3} \cdot$ Satoru Matsunaga ${ }^{2,4} \cdot$ Seikou Shintani ${ }^{2,3} \cdot$ Shinichi Abe ${ }^{2,4}$. \\ Yuko Nitahara-Kasahara ${ }^{5} \cdot$ Atsushi Watanabe $^{6} \cdot$ Yukihiko Hirai $^{7} \cdot$ Takashi Okada $^{7}$ - Akira Yamaguchi ${ }^{2,8}$. \\ Masataka Kasahara ${ }^{1,2}$
}

Received: 20 January 2020 / Accepted: 9 February 2020 / Published online: 19 February 2020

(c) The Author(s) 2020

\begin{abstract}
Hypophosphatasia (HPP) is a systemic skeletal disease caused by mutations in the gene encoding tissue-nonspecific alkaline phosphatase (TNALP). We recently reported that survival of HPP model mice can be prolonged using an adeno-associated virus (AAV) vector expressing bone-targeted TNALP with deca-aspartate at the $\mathrm{C}$ terminus (TNALP-D ${ }_{10}$ ); however, abnormal bone structure and hypomineralization remained in the treated mice. Here, to develop a more effective and clinically applicable approach, we assessed whether transfection with TNALP- $\mathrm{D}_{10}$ expressing virus vector at a higher dose than previously used would ameliorate bone structure defects. We constructed a self-complementary AAV8 vector expressing TNALP driven by the chicken beta-actin (CBA) promoter (scAAV8-CB-TNALP-D 10 ). The vector was injected into both quadriceps femoris muscles of newborn HPP mice at a dose of $4.5 \times 10^{12}$ vector genome (v.g.)/body, resulting in $20 \mathrm{U} / \mathrm{mL}$ of serum ALP activity. The $4.5 \times 10^{12} \mathrm{v}$.g./body-treated HPP mice grew normally and displayed improved bone structure at the knee joints in X-ray images. Micro-CT analysis showed normal trabecular bone structure and mineralization. The mechanical properties of the femur were also recovered. Histological analysis of the femurs demonstrated that ALP replacement levels were sufficient to promote normal, growth plate cartilage arrangement. These results suggest that AAV vector-mediated high-dose TNALP- $\mathrm{D}_{10}$ therapy is a promising option for improving the quality of life (QOL) of patients with the infantile form of HPP.
\end{abstract}

Keywords Hypophosphatasia $\cdot$ Adeno-associated virus vector $\cdot$ Enzyme replacement therapy $\cdot$ Alkaline phosphatase $\cdot$ Bone structure

Electronic supplementary material The online version of this article (https://doi.org/10.1007/s00223-020-00676-5) contains supplementary material, which is available to authorized users.

Aki Nakamura-Takahashi

atakahashi@tdc.ac.jp

Masataka Kasahara

mkasahar@tdc.ac.jp

1 Department of Pharmacology, Tokyo Dental College, 2-9-18, Kandamisaki-cho, Chiyoda-ku, Tokyo 101-0061, Japan

2 Tokyo Dental College Research Branding Project, Tokyo Dental College, Tokyo, Japan

3 Department of Pediatric Dentistry, Tokyo Dental College, Tokyo, Japan

\author{
Abbreviations \\ AAV Adeno-associated virus \\ ALP Alkaline phosphatase \\ CBA Chicken beta-actin \\ EGFP Enhanced green fluorescence protein
}

4 Department of Anatomy, Tokyo Dental College, Tokyo, Japan

5 Department of Molecular Therapy, National Center of Neurology and Psychiatry, National Institute of Neuroscience, Tokyo, Japan

6 Division of Clinical Genetics, Kanazawa University Hospital, Ishikawa, Japan

7 Division of Molecular and Medical Genetics, The Institute of Medical Science, University of Tokyo, Tokyo, Japan

8 Oral Health Science Center, Tokyo Dental College, Tokyo, Japan 


\section{ERT Enzyme replacement therapy \\ FEA Finite element analysis \\ GPI Glycosylphosphatidylinositol \\ HPP Hypophosphatasia \\ PCR Polymerase chain reaction \\ QOL Quality of life \\ ROI Region of interest \\ TNALP Tissue-nonspecific alkaline phosphatase \\ TNALP-D ${ }_{10}$ Bone-targeted tissue-nonspecific alkaline phosphatase with deca-aspartate at the $\mathrm{C}$ terminus}

\section{Introduction}

Hypophosphatasia (HPP) is a rare congenital disease caused by mutations in the gene encoding tissue-nonspecific alkaline phosphatase (TNALP) [1, 2]. HPP is characterized by defective calcification of hard tissue, pathologic fracture, dyspnea, seizures, and premature tooth loss [3, 4]. It is classified into six different types according to the age at onset and symptoms: perinatal severe HPP, perinatal benign HPP, infantile HPP, childhood HPP, adult HPP, and odonto-HPP [5, 6], with perinatal severe HPP and childhood HPP frequently being fatal $[7,8]$. However, treatment for HPP has not been well established.

Whyte et al. first applied enzyme replacement therapy (ERT) by infusion of alkaline phosphatase (ALP)-rich plasma to an infantile patient with HPP [9]. In 2008, Millán et al. developed a novel ERT using bioengineered TNALP. The novel construct was formed by detaching the glycosylphosphatidylinositol (GPI) anchor from TNALP to allow secretion and adding a deca-aspartate motif to the $\mathrm{C}$ terminus (TNALP-D 10 ) to increase affinity for bone [10]; the latter was possible because TNALP is an ectoenzyme whose $\mathrm{C}$ terminus is anchored to the cell surface by a GPI anchor glycoprotein composed of approximately 500 amino acid residues [11]. This method clearly improved the phenotype of TNALP-deficient mice [10]. Furthermore, this method was applied to patients with HPP and was effective in prolonging life span $[12,13]$. In 2015, therapy with TNALP-D ${ }_{10}$ was approved for the treatment of HPP in Canada, Europe, Japan, and the USA. Although this therapy is effective in extending life and enabling patients to be weaned from artificial ventilation $[14,15]$, further improvements are necessary to address the following issues: (1) the HPP patient needs to receive repeated subcutaneous injections three times a week due to the short half-life of the enzyme [12], (2) the replacement enzyme dose must be increased as the patient grows, and (3) they have to continue treatment for life [16].

To resolve these problems, several approaches have been taken to establish a gene-based therapy to replace the enzyme. We have explored this approach using various viral vectors in $A k p 2^{-/-}$(TNALP-knockout) HPP model mice, as they exhibit dyspnea, seizures, growth failure, and bone hypoplasia, resulting in death within 3 weeks of birth [17]. Recently, Nakano et al. showed that gene correction of induced pluripotent stem cells (iPS cells) isolated from two HPP patients rescued ALP activity and mineralization in vitro [18], suggesting a possible application of genecorrected iPS cells for patients with HPP. These in vivo and in vitro experimental systems provide opportunities to develop a new therapy that complement the disadvantages of ERT.

Our previous studies demonstrated that a single injection of adeno-associated virus (AAV) vector, which is not pathogenic to humans and is very safe, expressing TNALP- $\mathrm{D}_{10}$ in an $A k p 2^{-/-}$HPP model mice successfully extended survival and corrected skeletal phenotype [19, 20]. However, several insufficient therapeutic effects were observed in skeletal tissues including hypomineralization of bone and cartilage, irregularly arranged trabeculae, partial cortical bone defects, and abnormal chondrocyte layer proliferation [20]. Although these problems are not directly life-threatening, improved treatment methods are required to prevent severely diminished physical activity.

We conjectured the non-completeness of therapeutic effects observed in the previous study [20] might be caused by insufficient local replacement of ALP in the bone and cartilage. In this study, to validate our assumption, we determined the optimal AAV vector dose for increasing the local ALP concentration in bone and mitigating femoral elongation, morphological irregularity and hypomineralization. Furthermore, we investigated the efficacy of this dose in terms of mechanical properties of the femur and spontaneous locomotor activity.

\section{Methods}

\section{Plasmid Construction and AAV Vector Production}

The recombinant self-complementary AAV (scAAV) vector plasmid, pscAAV-CB-EGFP, was provided by Dr. Arun Srivastava of the University of Florida College of Medicine (Gainesville, FL, USA). The plasmid pscAAV-CB-TNALP$\mathrm{D}_{10}$ was constructed by replacing the enhanced green fluorescence protein (EGFP) region of pscAAV-CB-EGFP with the AgeI-HindIII fragment (TNALP-D ${ }_{10}$ gene) of pAAVCAGS-TNALP-D $_{10}$ using an In-Fusion HD Cloning Kit (Clontech Laboratories, TaKaRa Bio Company, Ohtsu, Shiga, Japan). Recombinant scAAV8-CB-TNALP-D ${ }_{10}$ was generated using polyethylenimine-based adenovirus-free triple transfections of HEK293 cells in serum-free medium [21]. The AAV vector titer was determined using realtime polymerase chain reaction (PCR) using a 7500 Fast 
Real-Time PCR Instrument (Applied Biosystems, Carlsbad, CA) with the following primers for the TNALP-D ${ }_{10}$ gene: forward, 5'-CCGTGGCAACTCTATCTTT-3' and reverse, 5'-GAGACATTCTCTCGTTCACC-3'.

\section{Animal Procedures and Vector Injection}

TNALP-knockout $A k p 2^{-/-}$mice and $A k p 2^{+/+}$mice were obtained by mating $A k p 2^{+/-}$mice with mice with a mixed genetic background of 129/J and C57BL/6 J, which were generated in the Millán laboratory (La Jolla, CA) [17]. All mice were fed ad libitum a rodent diet supplemented with $325 \mathrm{ppm}$ pyridoxine (vitamin B6)/10 kg of feed (Oriental Yeast Co., Ltd., Tokyo, Japan) to suppress seizures [22]. Genotyping was performed using PCR with the following primers immediately after birth: forward, $5^{\prime}$-AGTCCG TGGGCATTGTGACTA-3'; and reverse, 5'-TGCTGCTCC ACTCACGTCGAT- $3^{\prime}$. To characterize the expression of TNALP-D ${ }_{10}$, scAAV8-CB-TNALP-D ${ }_{10}$ was injected into both quadriceps femoris muscles of neonatal $A k p 2^{-/-}$mice on day 1 after birth. The amount of vector injected was $1.5 \times 10^{11}(n=8), 7.5 \times 10^{11}(n=7), 1.5 \times 10^{12}(n=7)$, or $4.5 \times 10^{12}(n=7)$ vector genomes (v.g.)/body diluted with phosphate-buffered salts (PBS) to a total volume of $20 \mu \mathrm{L}$. The physical appearance of the mice was observed regularly, and body weight was measured every 10 days for 90 days. To examine the therapeutic effects of scAAV8-CB-TNALP$\mathrm{D}_{10}$, the treated $A k p 2^{-/-}$mice were sacrificed at 90 days of age and perfused with $15 \mathrm{~mL}$ of PBS. Tissue samples were taken from the heart, liver, lung, spleen, kidney, quadriceps femoris muscle, genitalia, bone (both hind limbs), and brain. $A k p 2^{+/+}$mice of the same age were used as controls $(n=7)$.

\section{ALP Activity in Serum}

Blood samples were collected from the tail vein or inferior vena cava using a 29-gauge insulin syringe on days 30,60 , and 90 after birth $(n=7)$. ALP activity in the serum was measured using a colorimetric assay, as described previously [23], with $1 \mathrm{U}$ being the amount of enzyme needed to catalyze the generation of $1 \mu \mathrm{mol} p$-nitrophenol per min.

\section{X-ray Analysis}

All the radiographic images were recorded on $\mu \mathrm{FX}-1000$ film (Fujifilm, Tokyo, Japan). Imaging conditions were as follows: tube voltage, $25 \mathrm{kV}$; tube current, $100 \mu \mathrm{A}$; exposure time, $30 \mathrm{~s}$ [20]. At 90 days after birth, hind limbs were X-ray irradiated and imaged with a Typhoon FLA-7000 scanner (Fujifilm) $(n=7)$.

\section{Micro-computed Tomography Imaging}

Micro-computed tomography (micro-CT) analysis was performed using an TDM-1000 scanner (Yamato Scientific, Tokyo, Japan). Imaging conditions were as follows: matrix size, $1024 \times 1024$; tube voltage, $60 \mathrm{kV}$; tube current, $60 \mu \mathrm{A}$; magnification, $\times 3.5$; filter, $0.1 \mathrm{~mm}$ brass; slice pitch, $17 \mu \mathrm{m}$; voxel size, $17 \times 17 \times 17(\mu \mathrm{m})$. The growth plate and midshaft were selected as the scan site (midshaft $=$ half of the entire length) [24] $(n=5)$.

\section{Morphometric Evaluation of Trabecular Bone}

To analyze femur morphometry, we employed the 3D analytical software TRI/3D-BON (Ratoc System Engineering, Tokyo, Japan). The region of interest (ROI) was 1-mm-thick and positioned $0.5 \mathrm{~mm}$ above the growth plate. Bone mineral density, bone volume/tissue volume, trabecular number, trabecular thickness, trabecular separation, and marrow space star volume were semi-automatically determined in accordance with the guidelines for evaluation of bone microstructure using 3D images [24, 25].

\section{Histological Analysis}

Prepared knee joints were fixed in 4\% paraformaldehyde in PBS and embedded in Super Cryoembedding Medium compound (Leica Microsystems, Wetzlar, Germany). Then, they were frozen without decalcification. Sections 10- $\mu \mathrm{m}$-thick were prepared by the Kawamoto method [26] using Cryofilm Type IIC (9) (Leica Microsystems, Wetzlar, Germany), air-dried for $10 \mathrm{~min}$, washed with PBS, and further washed with distilled water. To examine cartilage structure, sections were stained with Alcian blue solution $\mathrm{pH} 2.5$ (Muto Pure Chemicals, Tokyo, Japan) for 30 min, washed with distilled water for $2 \mathrm{~min}$, and counterstained with Kernechtrot (nuclear fast red) stain solution (Muto Pure Chemicals) for $1 \mathrm{~min}$. Standard hematoxylin and eosin (H\&E) staining was performed for histological observation. To analyze ALP replenishment areas, sections were stained using an ALPstaining kit (Muto Pure Chemicals) for $120 \mathrm{~min}$ at $37^{\circ} \mathrm{C}$. Sections were mounted on MAS-coated glass slides (Matsunami Glass, Tokyo, Japan) and examined under a light microscope $(n=5)$.

\section{Finite Element Analysis}

The reconstructed 3D-images obtained using micro-CT were exploited for finite element analysis (FEA). The ROI was set with the anterior-posterior axis as the $X$-axis, the internal-external axis as the $Y$-axis, and the major axis as the $Z$-axis. It was defined as a 2-mm-thick region spanning from $1.8 \mathrm{~mm}$ proximal to $0.2 \mathrm{~mm}$ distal to the growth plate. Using 
Carter's equation [27], the Young's modulus was set at $22 \mathrm{GPa}$ for cortical bone and $6 \mathrm{GPa}$ for trabecular bone, and the Poisson ratio was set at 0.30 for both bone types. A strain was applied to the entire proximal side of the cortical bone and trabecular bone. The element on this surface was restrained to 1 voxel. Bone fracture was defined as a minimal principal strain of $10 \%$ or more, and forced displacement was stopped when bone fracture reached $2 \%$ or more of bone volume [28]. Simultaneously, the total reaction force on the bottom surface (=fixed area) was analyzed as a fracture load using the TRI/3D-FEM64 FEA software (Ratoc System Engineering, Tokyo, Japan) [29] $(n=5)$.

\section{Spontaneous Locomotor Activity}

The spontaneous locomotor activity of mice was measured using a dual activity monitor system (Shinfactory, Fukuoka, Japan). This system comprised a rectangular enclosure (30 $\times 20 \mathrm{~cm}^{2}$ ) containing a wheel; the side wall of the enclosure had infrared sensors at 2-cm intervals [30]. The system was placed in a softly illuminated sound-proof room. At 85 days after birth, $A k p 2^{+/+}$mice, and $A k p 2^{-/-}$mice injected with AAV vector at $1.5 \times 10^{11}$ or $4.5 \times 10^{12} \mathrm{v} . g . /$ body, were put in the system. After 1 day of training, spontaneous movement was recorded for 5 days to determine planar movement (floor movement) count number, wheel movement rotational number, wheel movement total distance, wheel movement average speed (average running speed other than 0 ), wheel movement activity time, and wheel movement acceleration (maximum running speed); each parameter was calculated per day. The spontaneous locomotor activity analyses were carried out using a ACTIMO-DATAII software (Bio Research Center, Aichi, Japan) $(n=5)$.

\section{Statistical Analysis}

All data are presented as the mean \pm SD. Bartlett's test was used to confirm that the data showed a normal distribution and similar variance among groups. Differences between multiple groups were examined using one-way analysis of variance (single-factor ANOVA) and Tukey-Kramer post hoc tests. $P$ values less than 0.05 were considered statistically significant. Survival rates were estimated using the Kaplan-Meier method, and the differences in survival rates were examined using the log-rank test. Statistical analyses were conducted in Statcel 4 for Windows (OMS, Saitama, Japan).

\section{Results}

\section{Elevated Serum ALP Activity and Prolonged Survival in Akp2 ${ }^{-/-}$Mice Following Intramuscular Injection of SCAAV8-CB-TNALP-D 10}

The vector scAAV8-CB-TNALP-D ${ }_{10}$ was administered intramuscularly to $A \mathrm{kp} 2^{-/-}$mice at $1.5 \times 10^{11}, 7.5 \times 10^{11}$, $1.5 \times 10^{12}$, or $4.5 \times 10^{12}$ v.g./body on day 1 after birth. To determine ALP levels in the serum, ALP activity was measured via a colorimetric assay every 30 days after AAV vector injection. The serum ALP activity rapidly increased in all groups. The effect of the AAV vector was dose dependent: $A k p 2^{-/-}$mice treated at $1.5 \times 10^{11}, 7.5 \times 10^{11}, 1.5 \times 10^{12}$, or $4.5 \times 10^{12} \mathrm{v}$.g./body showed on average $1.69,1.94,8.45$, and $24.97 \mathrm{U} / \mathrm{mL}$ serum ALP activity, respectively, at day 90 after birth (Fig. 1a). High vector copy numbers were observed in the liver and in quadriceps femoris muscles (the injection
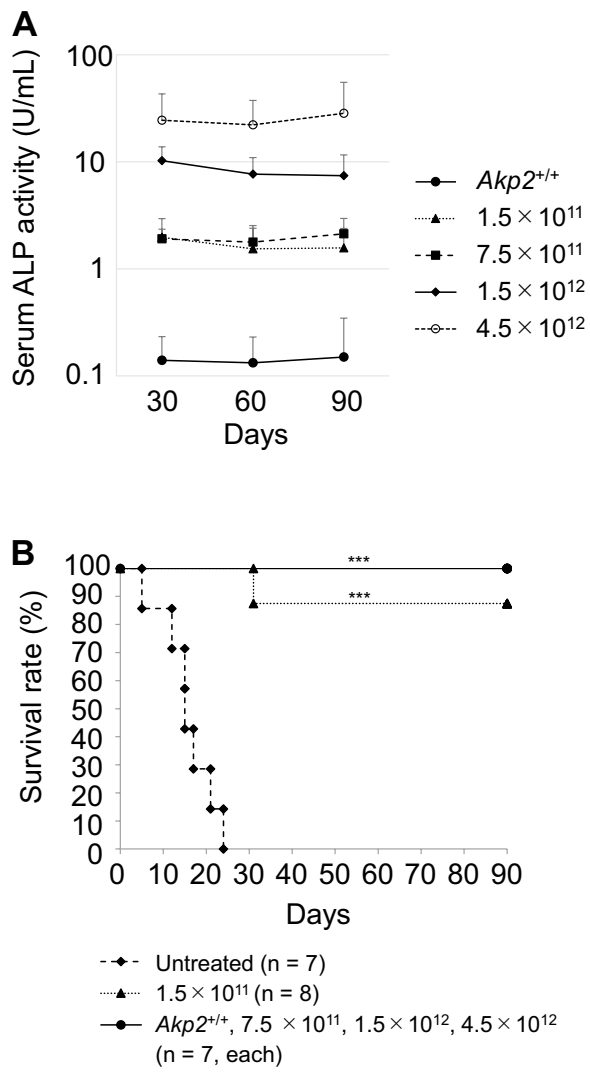

Fig. 1 Effect of TNALP-D ${ }_{10}$ dose on serum ALP activity and survival rate. $A k p 2^{-/-}$mice were untreated or injected with the indicated doses of AAV vector (scAAV8-CB-TNALP-D 10 ) at day 1 after birth. Untreated $A k p 2^{+/+}$mice were used as a control. a Serum ALP activity measured at the indicated days after birth. Error bars, SD $(n=7)$. b Kaplan-Meier survival analysis of AAV vector-treated $A k p 2^{-/-}$mice. Treatment with AAV vector at all test doses improved the survival rate significantly compared with that of untreated mice. $* * * P<0.001$ 
sites) (Fig. S1A). Moreover, ALP activity was very high in the quadriceps femoris muscle but low in the liver (Fig. S1B). Untreated $A k p 2^{-/-}$mice had a normal appearance but experienced epileptic seizures and hypomineralization by day 10 after birth and died within 3 weeks of birth. In contrast, treated mice displayed significantly prolonged survival rates at all vector doses $(P<0.001$, log-rank test) (Fig. 1b).

\section{Promotion of Weight Gain and Femur Elongation by a High Dose of TNALP-D 10}

Body weight and femur length were used to assess the growth of AAV vector-transduced mice. $A k p 2^{-1-}$ mice treated with a high dose $\left(4.5 \times 10^{12} \mathrm{v.g}\right.$./body $)$ of AAV vector achieved normal weight gain at day 90 after birth: that is, the body weight of the treated mice $(24.58 \pm 1.89 \mathrm{~g})$ was similar to that of the control mice $(24.78 \pm 2.49 \mathrm{~g})$. However, $A k p 2^{-I-}$ mice treated with lower doses showed stagnated weight gain after day 20 (Fig. 2a); the differences in body weight between these groups and the control mice were significant at day 90 (>5 g difference; Fig. 2b). In X-ray images taken at day 90 , irregular shapes of the knee joint were seen in the hind limbs of mice treated with the lowest dose $\left(1.5 \times 10^{11} \mathrm{v} . \mathrm{g} . /\right.$ body $)$ and two middle doses $\left(7.5 \times 10^{11}\right.$ v.g./body and $1.5 \times 10^{12}$ v.g./body) of AAV vector; conversely, control mice and mice treated with the highest does $\left(4.5 \times 10^{12} \mathrm{v} . \mathrm{g} . / \mathrm{body}\right)$ exhibited normal knee joint formation (Fig. 2c). Femur lengths did not differ significantly between mice treated with $4.5 \times 10^{12} \mathrm{v}$.g./body $(14.02 \pm 0.43 \mathrm{~mm})$ and control mice $(14.66 \pm 0.38 \mathrm{~mm})$; however, mice treated with
Fig. 2 Effect of TNALP-D high-dose on growth. Akp2 $2^{-I-}$ mice were untreated or injected with the indicated doses of AAV vector (scAAV8-CBTNALP-D ${ }_{10}$ ) at day 1 after birth. Untreated $A k p 2^{+/+}$mice were used as a control. a All mice were weighed after birth and then every 10 days until day 90 . The growth curve of Akp2 $2^{-1-}$ mice treated with $4.5 \times 10^{12}$ v.g./body vector was similar to that of the control mice. Error bars, SD (male, $n=4$; female, $n=3$ ). b Weight comparison of each group at 90 days after birth. Mice treated with $4.5 \times 10^{12} \mathrm{v}$.g./ body showed a similar weight gain to that of the control mice. Error bars, SD (male, $n=4$; female, $n=3)$. $* P<0.05$; $* * P<0.01$ : NS, not significant. c Representative X-ray images of the hind limbs of mice treated with $4.5 \times 10^{12} \mathrm{v} . \mathrm{g} . /$ body, taken at 90 days after birth; the bone structure at the joint showed normal morphology. Whereas irregular shapes of the knee joint is seen in the hind limbs of mice treated with the lower doses $\left(1.5 \times 10^{11}\right.$ v.g./body, $7.5 \times 10^{11}$ v.g./body and $1.5 \times 10^{12} \mathrm{v} . \mathrm{g} . /$ (body) of $\mathrm{AAV}$ vector. White arrows are irregular knee shape. Scale bars, $4 \mathrm{~mm}$. d Femur lengths of mice treated with $4.5 \times 10^{12}$ v.g.I body AAV vector were similar to those of control mice. Error bars, $\mathrm{SD}(n=7)$. $* * P<0.01$ : NS, not significant
A

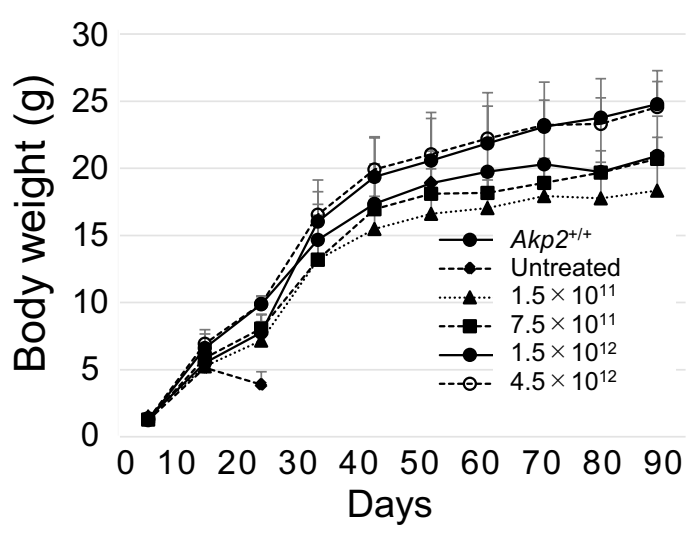

B

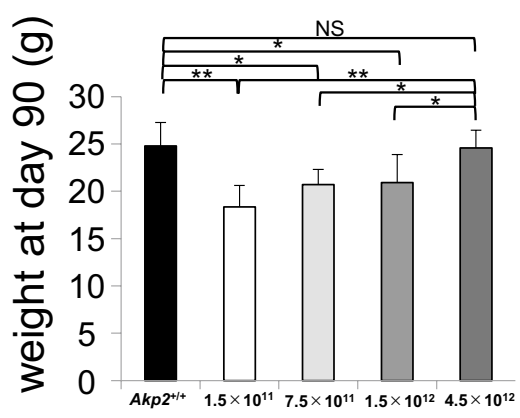

C
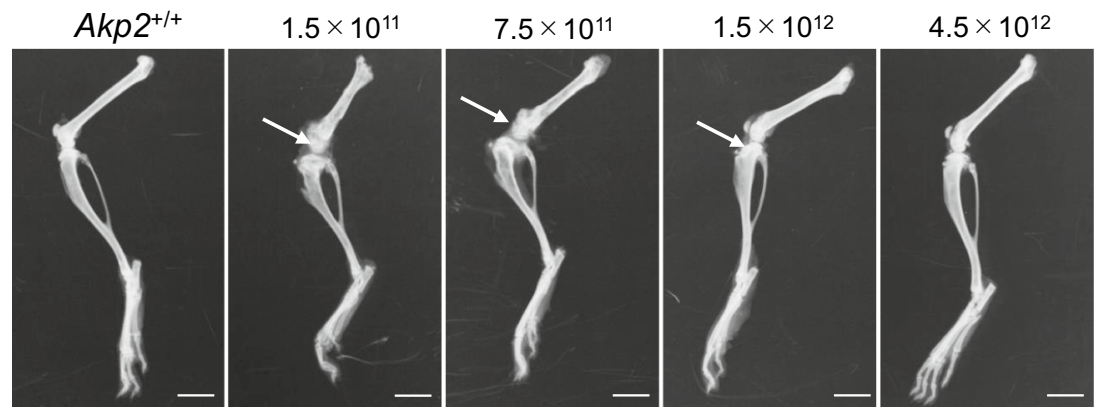

D

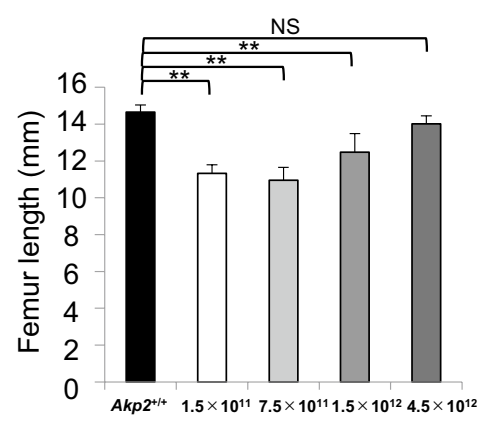


lower doses had significantly shorter femurs than control mice ( $>2$ mm difference; all $P<0.01$; Fig. $2 \mathrm{~d}$ ).

\section{Restoration of Normal Bone Structure and Bone Quality Upon Administration of High Dose of TNALP-D 10}

We conducted a micro-CT analysis of the femoral structure in $A k p 2^{-/-}$mice treated with AAV vector at $1.5 \times 10^{11}$ v.g./ body or $4.5 \times 10^{12} \mathrm{v} . \mathrm{g} . /$ body. The images showed irregular shape of growth plate, decrease in trabecular bones and defect and thinning of cortical bone in the mice treated with $1.5 \times 10^{11} \mathrm{v}$.g./body. In contrast, these morphological abnormalities were not observed in mice treated with $4.5 \times 10^{12}$ v.g./body; these mice exhibited the same bone structure as the control mice (Fig. 3a). In trabecular bone analysis of the ROI, images indicated that mice exhibited numerous cavities as a result of the low number of trabeculae and the bone
Fig. 3 Micro-CT analysis of the effect of TNALP-D ${ }_{10}$ high-dose on bone structure. Akp $2^{-/-}$mice were injected with the indicated dose of AAV vector (scAAV8CB-TNALP-D ${ }_{10}$ ) at day 1 after birth. Untreated $A k p 2^{+/+}$ mice were used as a control. a Representative micro-CT images of femur taken on day 90 after birth. Femurs of mice treated with $4.5 \times 10^{12} \mathrm{v}$.g./body displayed uniform cortical bone, and there were no differences in epiphyseal cupping compared with control mice. However, femur of mice treated with $1.5 \times 10^{12}$ v.g./body showed defects (white arrows) and thinning (yellow arrow) of cortical bone. White box indicates irregular shape of growth plate. Scale bars, $1 \mathrm{~mm}$. b Images of regions of interest (ROIs) in cancellous bone analysis. Trabecular arrangement in the ROI of the mice treated with $4.5 \times 10^{12}$ v.g./body was similar to that in the control mice. Scale bars, $1 \mathrm{~mm}$. c Morphometric evaluation of trabecular bone. In the mice treated with $4.5 \times 10^{12}$ v.g./body, all parameters examined were recovered to the same values as those in control mice. BMD, bone mineral density; $\mathrm{BV} / \mathrm{TV}$, bone volume/tissue volume; Tb.N, trabecular number; Tb.Th, trabecular thickness; Tb.Sp, trabecular separation; $V_{\mathrm{m}}^{*}$. Space, marrow space star volume. Error bars, SD $(n=5)$. $* P<0.05 ; * * P<0.01$ : NS not significant
A

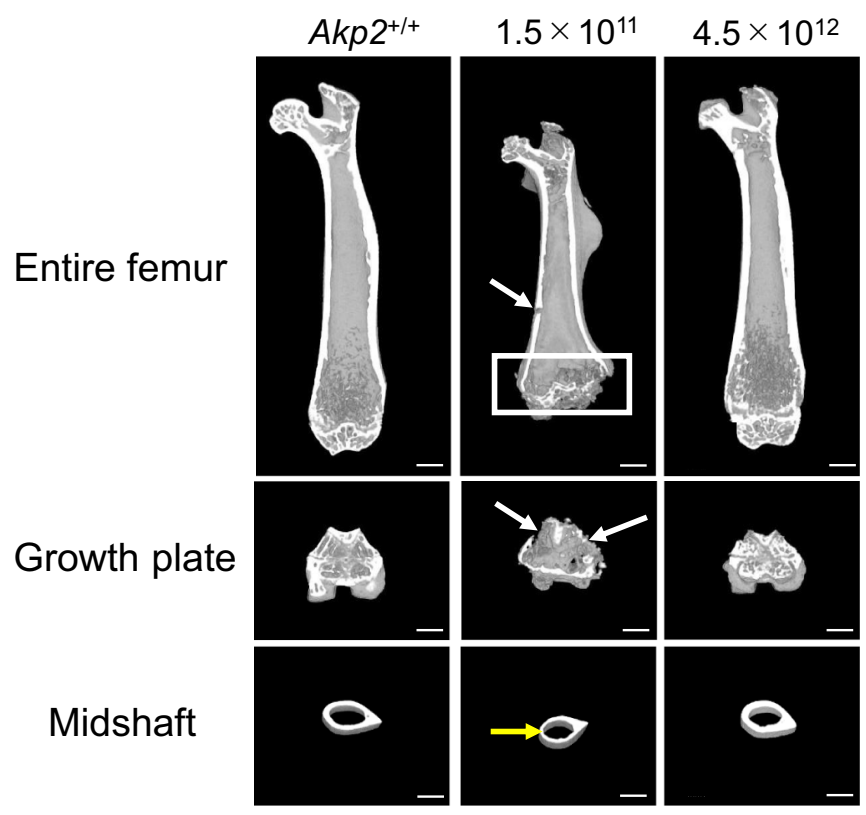

B
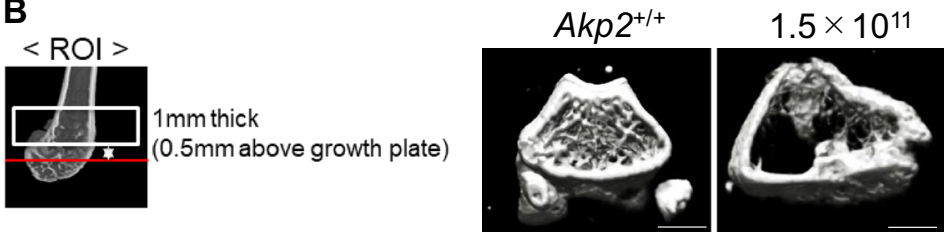

$4.5 \times 10^{12}$

C
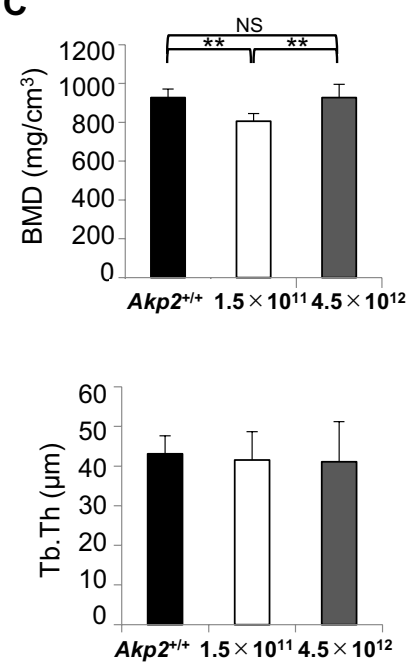
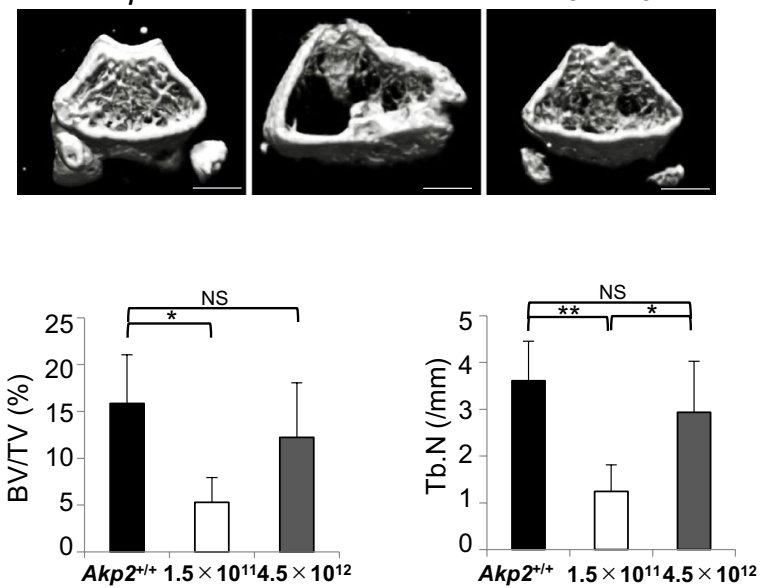

$A k p 2^{+/+} 1.5 \times 10^{11} 4.5 \times 10^{12}$

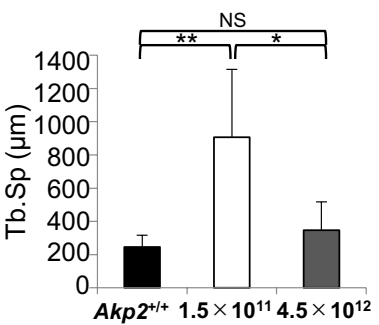


Fig. 4 Histological examination of the effect of TNALP-D $\mathrm{D}_{10}$ highdose on bone structure. $A k p 2^{-/-}$mice were injected with the indicated doses of AAV8 vector (scAAV8-CB-TNALP-D ${ }_{10}$ ) at day 1 after birth. Untreated $A k p 2^{+/+}$mice were used as a control $(n=5)$. a Alcian blue and Kernechtrot (nuclear fast red) staining of femur, growth plate, and epiphysis at 90 days after birth. The growth plate chondrocyte layer of mice treated with $4.5 \times 10^{12} \mathrm{v}$.g./body was regularly arranged, whereas mice treated with $1.5 \times 10^{11}$ v.g./body was irregular arranged. Scale bars: femur, $500 \mu \mathrm{m}$; growth plate, $200 \mu \mathrm{m}$; glenoid fossa, $200 \mu \mathrm{m}$. b Hematoxylin and eosin staining. Black arrows indicate ectopic fibrous tissue. Abnormal fibrous tissue was not observed in mice treated with AAV vector at $4.5 \times 10^{12}$ v.g./body. Scale bars: femur, $500 \mu \mathrm{m}$; glenoid fossa, $200 \mu \mathrm{m}$; and cortical bone, $200 \mu \mathrm{m}$. c ALP staining. Black arrows indicate weak positive spots for ALP. In mice treated at $4.5 \times 10^{12} \mathrm{v}$.g./body, the levels of serum ALP were sufficient for ALP to be distributed locally in the bone. Scale bars: femur, $500 \mu \mathrm{m}$; growth plate, $200 \mu \mathrm{m}$; glenoid fossa, $200 \mu \mathrm{m}$; cortical bone, $200 \mu \mathrm{m}$. d Ectopic structure images. Ectopic structures were detected in both mice treated with $1.5 \times 10^{11} \mathrm{v}$.g./body and those treated with $4.5 \times 10^{12} \mathrm{v}$.g./body. Black arrows indicate ectopic structure. Scale bars, $200 \mu \mathrm{m}$

width unusually wide in mice treated with $1.5 \times 10^{11} \mathrm{v}$.g./ body. In marked contrast, the bone structure was normal in mice treated with $4.5 \times 10^{12} \mathrm{v}$.g./body (Fig. $3 b$ ). Indeed, for all parameters measured in the trabecular bone analysis (bone mineral density, bone volume/tissue volume, trabecular number, trabecular thickness, trabecular separation, and marrow space star volume), the values in mice treated with $1.5 \times 10^{11} \mathrm{v}$.g./body were significantly lower than those in control mice and there was no significant difference between mice treated with $4.5 \times 10^{12}$ v.g./body and control mice (Fig. 3c).

\section{Normal Skeletal Structure in Histological Analysis Following a High Dose of TNALP-D 10}

To observe the condition of cartilaginous tissue, the growth plate and epiphysis of the femurs of treated mice were subjected to Alcian blue staining and Kernechtrot counterstaining. In $A k p 2^{-/-}$mice treated with $1.5 \times 10^{11}$ v.g./body, the growth plate cartilage was structurally disrupted and abnormally arranged, and the articular cartilage in the epiphysis was abnormally thick. In contrast, the arrangement of the growth plate cartilage and the thickness of articular cartilage in the epiphysis in $A k p 2^{-/-}$mice treated with $4.5 \times 10^{12} \mathrm{v} . \mathrm{g} . /$ body was similar to that in control mice (Fig. 4a). Ectopic fibrous tissue was observed in $\mathrm{H} \& \mathrm{E}$ staining images of the epiphysis and cortical bone in mice treated with $1.5 \times 10^{11}$ v.g./body, but not in those treated with $4.5 \times 10^{12} \mathrm{v}$.g./body or in control mice (Fig. 4b).

We performed ALP staining of the growth plate, epiphysis, and cortical bone in the femurs of $A k p 2^{-/-}$mice treated with $1.5 \times 10^{11}$ or $4.5 \times 10^{12}$ v.g./body. The ALP distribution in mice treated with $4.5 \times 10^{12} \mathrm{v}$.g./body was similar to that in control mice: i.e., ALP was distributed
A

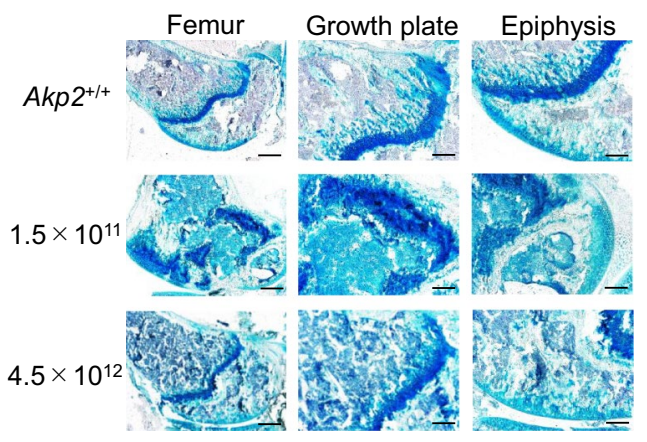

B
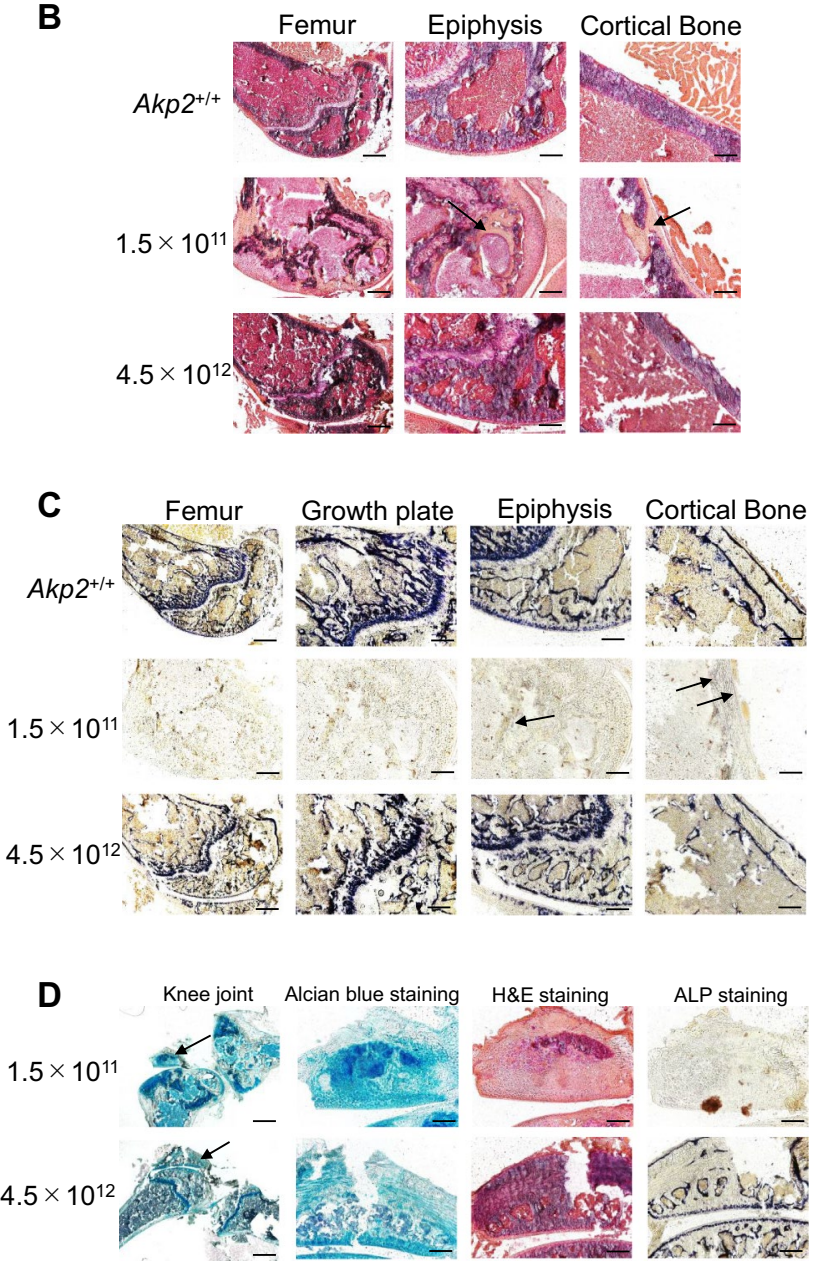

in the hypertrophic chondrocyte layer of the growth plate, the surface of glenoid trabecular bone, and the periosteum. However, only a few weak spots of ALP were observed in mice treated with $1.5 \times 10^{11}$ v.g./body (Fig. $4 \mathrm{c}$ ). Ectopic structures were not observed in control mice but were observed in the knee joint or cortical bone near the knee joint in mice treated with $1.5 \times 10^{11}$ or $4.5 \times 10^{12} \mathrm{v}$.g./body. The properties of ectopic structures differed between mice treated with $1.5 \times 10^{11}$ and those treated with $4.5 \times 10^{12}$ v.g./body, as outlined below. The ectopic structures in mice treated with $1.5 \times 10^{11}$ were restricted to irregular 
chondrocytes; ALP staining was negative and mineralization was not observed. In contrast, the ectopic structures in mice treated with $4.5 \times 10^{12}$ were ectopic bones, in which the trabecular bone construction and detected surface of trabecular bone were ALP positive (Fig. 4d).

\section{Ability of Femoral Strength to Withstand Normal Mechanical Stress Following High Doses of TNALP-D ${ }_{10}$}

We performed FEA of the femur epiphysis in $A k p 2^{-/-}$mice treated with $1.5 \times 10^{11}$ or $4.5 \times 10^{12} \mathrm{v}$.g./body; the ROI and analytical conditions are shown in Fig. 5a. The bone strength (fracture load) of mice treated with $1.5 \times 10^{11} \mathrm{v}$.g./ body was significantly lower than that of control mice. In contrast, the bone strength of mice treated with $4.5 \times 10^{12}$ v.g./body mice did not differ significantly from that of control mice (Fig. 5b).

A

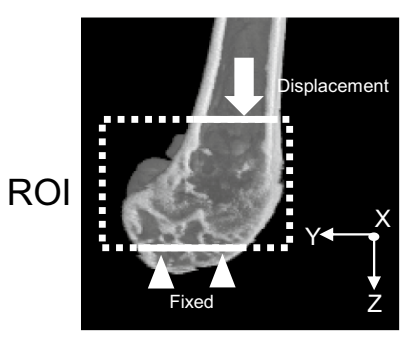

B

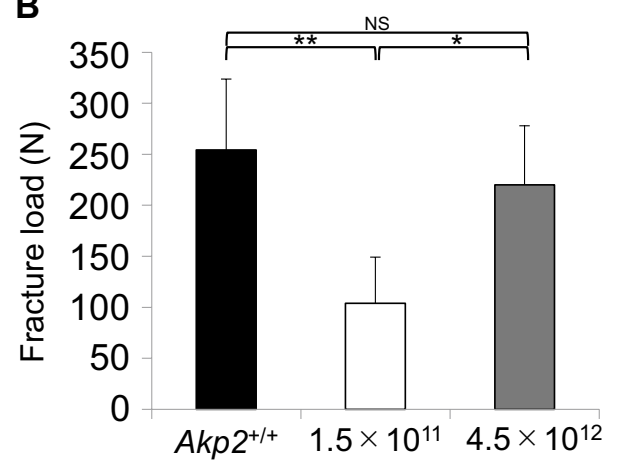

Fig. 5 FEA assessment of the effect of TNALP-D $\mathrm{D}_{10}$ high-dose on femoral strength. $A k p 2^{-/-}$mice were injected with the indicated doses of AAV vector (scAAV8-CB-TNALP-D ${ }_{10}$ ) at day 1 after birth. Untreated $A k p 2^{+/+}$mice were used as a control $(n=5)$. a Schematic of a region of interest (ROI) and analytical conditions. $X$-axis, anterior-posterior axis; $Y$-axis, internal-external axis; $Z$-axis, major axis. b Fracture load was determined by FEA at 90 days after birth. The femurs of mice treated with $4.5 \times 10^{12} \mathrm{v} . \mathrm{g}$./body could tolerate mechanical stress to a similar level as those of control mice. Error bars, SD. $* P<0.05 ; * * P<0.01: N S$ not significant
Failure to Restore Normal Spontaneous Locomotor Activity with a High Dose of TNALP-D ${ }_{10}$

Using a wheel cage, we investigated the spontaneous locomotor activity of $A k p 2^{-1-}$ mice treated with AAV vector at $1.5 \times 10^{11}$ or $4.5 \times 10^{12} \mathrm{v}$.g./body (Fig. 6 ). The present study is the first to include a long-term analysis of spontaneous activity. There was no significant difference in the planar movement count number between the AAV-treated mice and the control mice. However, wheel movement was significantly lower in terms of rotation number, total distance, and activity time in both mice treated with $1.5 \times 10^{11} \mathrm{v} . \mathrm{g}$./body and those treated with $4.5 \times 10^{12} \mathrm{v} . \mathrm{g} . /$ body than in control mice.

\section{Discussion}

In previous studies, we successfully prolonged the survival of HPP mice by TNALP- $\mathrm{D}_{10}$ replacement via the single administration of lentivirus vector [31] or an AAV vector $[19,20]$. However, detailed analysis of the femurs of these mice revealed issues, including morphological irregularity, insufficient extension, and hypomineralization, suggesting that the condition was not fully resolved and that the AAV vector dosage may have been suboptimal [20]. Considering the application to patients with HPP, these results suggested that suboptimal dose would not prevent patients from suffering from growth impairment leading to short stature and persistent susceptibility to fractures. Because the most severe type of HPP affects infants and young children at an age when they are growing rapidly, growth impairment causing short stature is psychologically distressing for both patients and their families, and persistent susceptibility to fractures leads to skeletal deformity and ultimately contributes to impaired physical function. Accordingly, although these problems are not life-threatening, they severely diminish the QOL of patients and their families [32-34]. Such impaired growth has already been observed in patients with HPP receiving the current enzyme replacement therapy, with data showing that their height and weight are greater than two standard deviations below the mean [14]. There is, therefore, a need to develop new treatment regimens capable of ameliorating the insufficient elongation, morphological irregularity, and hypomineralization of the femur by comparing the effects of ERT.

In this study, to investigate the optimum AAV vector dose needed to ameliorate femoral morphological irregularity and hypomineralization, we administered four different doses of scAAV8-CB-TNALP-D $10\left(1.5 \times 10^{11}, 7.5 \times 10^{11}\right.$, $1.5 \times 10^{12}$, or $4.5 \times 10^{12} \mathrm{v} . g . /$ body) by intramuscular injection into both quadriceps femoris muscles of HPP mice. All these doses increased serum ALP activity to over $1 \mathrm{U} /$ 
Fig. 6 Effect of TNALP-D ${ }_{10}$ dose on spontaneous movement. $A k p 2^{-l-}$ mice were injected with the indicated doses of AAV8 vector (scAAV8-CBTNALP-D 10 ) at day 1 after birth. Untreated $A k p 2^{+/+}$mice were used as a control. In terms of wheel movement rotation number (/day) and wheel movement total distance ( $\mathrm{m} /$ day), spontaneous movement was significantly lower in mice treated with both $1.5 \times 10^{11}$ v.g./body and $4.5 \times 10^{12}$ v.g./body than in the control mice. Error bars, SD $(n=5)$. $* P<0.05 ; * * P<0.01$ :

$N S$ not significant
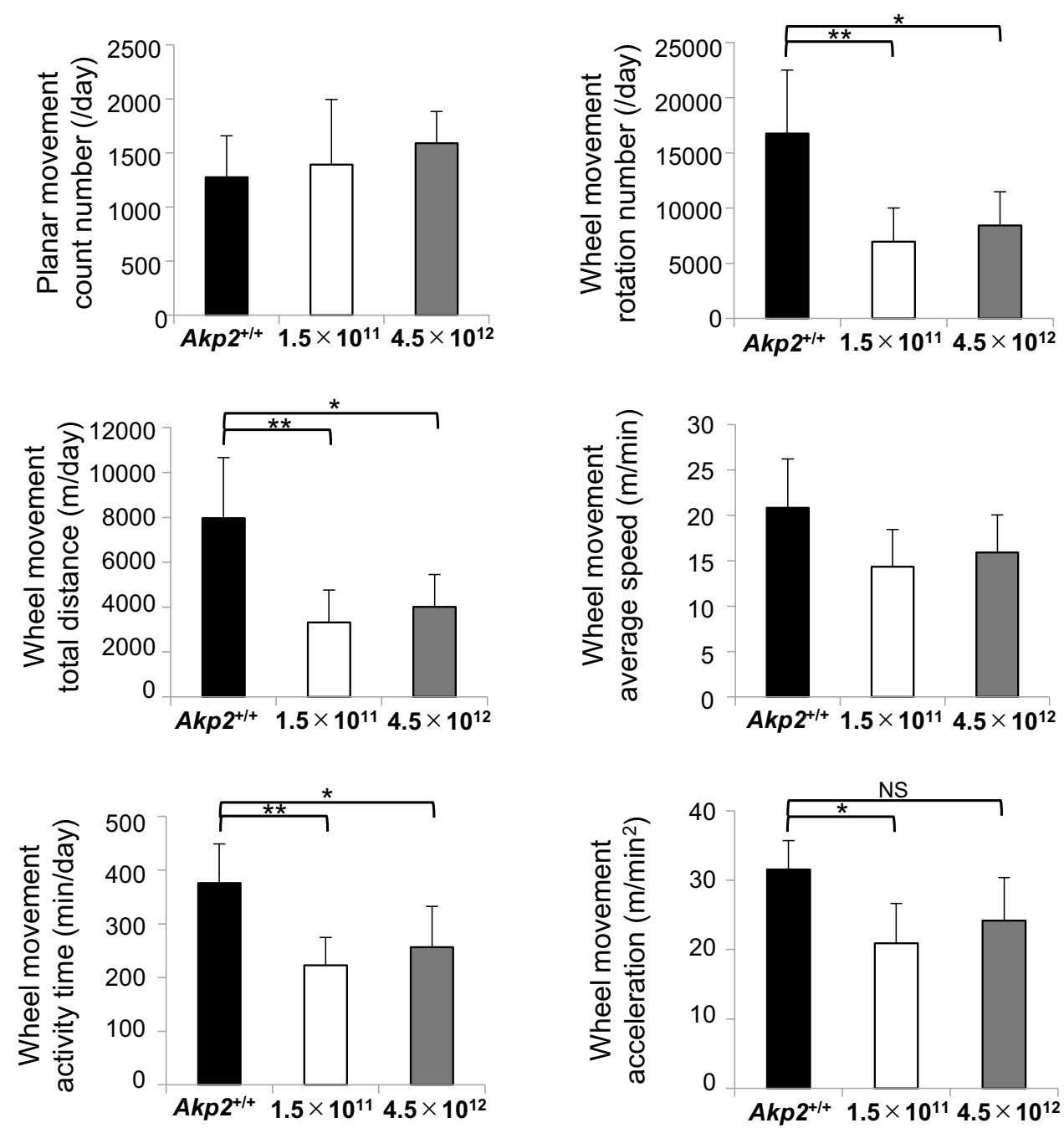

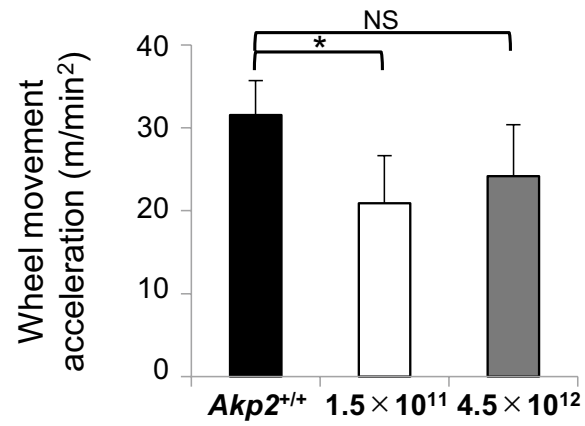

$\mathrm{mL}$, thereby prolonging survival of the mice. This result is consistent with previous reports [19, 20]. We observed high vector copy numbers in liver and injected muscle, and high-ALP activity in muscle. It is known from clinical trials in hemophilia B patients that transduction does not result in long-term sustained gene expression in the liver because of the immune reaction to the viral capsid [35]. On the basis of this observation, we assume that, although transduction of AAV vector is easily achieved in muscle and liver [21], it does not persist in the liver.

Normal body weight and femoral length were achieved only in HPP mice that received a dose of $4.5 \times 10^{12} \mathrm{v.g} . /$ body; those that received lower doses exhibited plateaus in weight gain and impaired femoral elongation. In previous discussions on enzyme replacement therapy in HPP mice, it has been argued that the lack of adipose tissue in treated mice results in a plateauing of weight gain that must be due to a mechanism other than morphological irregularities of bone [36]. However, data from this study showed that, like the control mice, HPP mice treated with $4.5 \times 10^{12}$ v.g./ body had normal-length femurs, and their weight gain did not plateau but continued to increase until they ultimately reached normal weight. These results suggest that persistent insufficient bone elongation is likely a direct cause of the plateau in weight gain. We performed a micro-CT analysis to observe the femoral morphology in greater detail. HPP mice treated with $1.5 \times 10^{11} \mathrm{v}$.g./body, which resulted in a serum ALP activity of $1 \mathrm{U} / \mathrm{mL}$ and was found to extend survival, exhibited morphological irregularities, including persistent epiphyseal cupping, irregularly arranged trabeculae, cortical bone defects, and non-uniform cortical bone thickness in previous studies [20]. Cancellous bone analysis confirmed that the disease also remained unresolved in quantitative terms. In contrast, HPP mice treated with $4.5 \times 10^{12}$ v.g./ body exhibited bone morphology that was almost identical to that of the control mice, and the values measured in the cancellous bone analysis and FEA also improved. These findings support the hypothesis that the level of serum ALP activity required to prolong survival $(1 \mathrm{U} / \mathrm{mL})$ is insufficient in terms of local ALP replacement in femoral bone. 
At this serum ALP level, the disease remains unresolved in a number of aspects, including insufficient elongation of the femur, epiphyseal cupping, irregularly arranged trabeculae, hypomineralization, and cortical bone defects. It also suggests that administering TNALP-D ${ }_{10}$ at a sufficiently high dose for local femoral bone may ameliorate these unresolved problems.

To evaluate the histological condition of bone, we conducted Alcian blue staining, H\&E staining, and ALP staining. In HPP mice treated with $1.5 \times 10^{11}$ v.g./body, histological staining revealed morphological irregularities in the growth plate cartilage and articular cartilage as well as ectopic fibrous tissue in the epiphysis and cortical bone, and there were only a few weak positive spots in the ALP staining. In contrast, mice treated with $4.5 \times 10^{12} \mathrm{v}$.g./body exhibited the same morphology and ALP distribution as those seen in the control group. This result lends further support to the hypothesis that TNALP-D ${ }_{10}$ replacement at a dose sufficient to achieve normal levels of ALP in local bone brings about normal calcareous degeneration of the hypertrophic chondrocyte layer, leading to normal endochondral ossification [37], and ameliorates insufficient elongation, morphological irregularity, and hypomineralization of the femur. In the present study, we applied the frozen sections (10 $\mu \mathrm{m}$ thick) obtained from unfixed and undecalcified bone tissues to detect more accurate ALP activity. This technique provided successful detection of ALP activity, but it failed to observe details of chondrocyte columnar arrangement due to the reduced resolution of histology. Application of more advanced technique to detect accurate ALP activity retaining detailed morphology will be necessary to compare accurate therapeutic effects between ERT and gene therapy at histological level.

In the bone strength analysis of the epiphyseal ROI in HPP mice treated with $1.5 \times 10^{11} \mathrm{v}$.g./body, we found that the growth plate and trabeculae were unable to absorb the mechanical stress generated by forced displacement and exhibited extremely fragile structural characteristics compared with those of control mice. In contrast, in HPP mice treated with $4.5 \times 10^{12} \mathrm{v}$.g./body, which had bone morphology almost identical to that of the control group, these areas were able to withstand displacement to a level comparable to that of the control group. This finding suggests that the persistence of cortical bone defects, reduced trabecular numbers, and irregularly arranged trabeculae observed in HPP mice treated with suboptimal doses of vector may interfere with one of the most important functions of bone-its role as a supporting tissue maintaining the body's structure against its own weight.

Although femoral morphology was improved in HPP mice treated with $4.5 \times 10^{12} \mathrm{v}$.g./body, histological analysis unexpectedly revealed the presence of ectopic bone structures in these mice, which will be an adverse effect of the treatment. We speculate that these structures relate to the timing of the start of treatment. Because treatment began neonatally, endochondral ossification in utero went untreated, and hypertrophic chondrocytes did not undergo calcareous degeneration, and overproliferated. As a result, overproliferated cartilages of the epiphysis may have separated when force was applied. The ectopic calcification seen in the HPP mice treated with $4.5 \times 10^{12} \mathrm{v}$.g./body may have been formed by TNALP-D 10 replacement in this detached cartilage. This issue might be resolved by starting the treatment in utero, and we are now planning to conduct fetal gene therapy experiments. Here, we found that a high dose of $4.5 \times 10^{12} \mathrm{v}$.g./body was required to provide sufficient ALP replacement in local bone to ameliorate the signs of HPP. In gene therapy using large animals, intravenous administration of high doses of AAV vectors reportedly causes liver toxicity $[38,39]$. This toxicity is likely caused not only by the presence of contaminating proteins or the method of viral vector preparation [40, 41] but also by the viral load or promotor sequence [39]. Previous studies have found that the treatment vector is more easily introduced into bone when gene therapy is conducted in utero rather than neonatally [42]. Investigating in utero gene therapy could enable a lower dose of the vector to be administered, which is desirable from a safety perspective.

The symptoms of HPP patients include muscle weakness and muscle pain, and many patients exhibit delayed or impaired motor development [43, 44]. Here, although there was no significant difference in activity levels on the floor between the control mice and HPP mice treated with AAV vector at $1.5 \times 10^{11}$ or $4.5 \times 10^{12} \mathrm{v} . \mathrm{g} . / \mathrm{body}$, we found that the activity in the wheel cage was lower in HPP mice at all treatment doses examined than in control mice. We previously reported that activity was restored in the treated HPP mice [20]; however, in that study, we performed only a shortterm analysis of activity levels on the floor. Our investigation of daily spontaneous activity in a wheel cage provided the important knowledge that the activity level does not, in fact, recover, even in mice treated with $4.5 \times 10^{12} \mathrm{v}$.g./body. Given our finding that the structure and strength of bone did recover in these mice, we considered that joint or muscle abnormalities may be present. Attempts have recently been made to create large-animal models of HPP, and the successful establishment of an ovine HPP model using CRISPR/Cas9 has been reported [45]. At 2 months of age, the HPP model sheep showed signs of muscle weakness, with a qualitatively altered gait, and skeletal muscle biopsy revealed abnormalities in muscle fiber size and incorrectly folded mitochondrial cristae [45]. Myopathy has also been reported in HPP patients, with muscle biopsy revealing no abnormalities in some cases [46] but abnormalities in muscle fiber size in others [43]. This mechanism is currently under investigation. 


\section{Conclusion}

In this study, injection of model HPP mice with scAAV8CB-TNALP-D ${ }_{10}$ at an optimal high dose resulted in high levels of bone ALP activity and induced normal growth and improved bone formation. Therefore, optimized AAV vector-mediated TNALP- $\mathrm{D}_{10}$ replacement therapy is a promising option for improvement of the QOL of patients with the infantile form of HPP. Further studies concerning the comparison of the therapeutic effect between our gene therapy and ERT are necessary using $A k p 2^{-/-}$mice before clinical application.

Acknowledgements We thank Arun Srivastava of the University of Florida College of Medicine for providing the plasmid pscAAV-CBEGFP (formerly reported as pdsAAV-CB-EGFP). We thank James Wilson of the University of Pennsylvania for providing the AAV packaging plasmid. We thank Dr. Jose Luis Millán and Dr. Sonoko Narisawa at the Sanford-Burnham Medical Research Institute for providing the $A k p 2^{-/-}$mice. This work was supported by JSPS KAKENHI [Grant Numbers JP16H07213, JP19K18970], a Tokyo Dental College President's Encouragement Research Grant, and the Tokyo Dental College Research Branding Project.

Author Contributions AN-T: Conceptualization, Methodology, Validation, Formal analysis, Investigation, Data Curation, Writing-Original, Visualization, Supervision, Project administration, Funding acquisition. TT: Investigation, Data Curation, Writing-Review \& Editing Satoru Matsunaga: Methodology, Validation, Formal analysis, Investigation, Data Curation, Writing-Review \& Editing, Funding acquisition. SS: Data Curation, Writing-Review \& Editing. SA: Data Curation, Writing-Review \& Editing. YN-K: Methodology, Writing-Review \& Editing. AW: Writing-Review \& Editing. YH: Methodology, Resources, Writing — Review \& Editing. TO: WritingReview \& Editing. AY: Data Curation, Writing-Review \& Editing and MK: Conceptualization, Data Curation, Writing-Review \& Editing, Supervision, Project administration.

\section{Compliance with Ethical Standards}

Conflict of interest Aki Nakamura-Takahashi, Toshiki Tanase, Satoru Matsunaga, Seikou Shintani, Shinichi Abe, Yuko Nitahara-Kasahara, Atsushi Watanabe, Yukihiko Hirai, Takashi Okada, Akira Yamaguchi, Masataka Kasahara declare that they have no conflict of interest.

Human and Animal Rights and Informed Consent All experiments were approved by the Animal Research Ethics Committee at Tokyo Dental College (No. 300706).

Open Access This article is licensed under a Creative Commons Attribution 4.0 International License, which permits use, sharing, adaptation, distribution and reproduction in any medium or format, as long as you give appropriate credit to the original author(s) and the source, provide a link to the Creative Commons licence, and indicate if changes were made. The images or other third party material in this article are included in the article's Creative Commons licence, unless indicated otherwise in a credit line to the material. If material is not included in the article's Creative Commons licence and your intended use is not permitted by statutory regulation or exceeds the permitted use, you will need to obtain permission directly from the copyright holder. To view a copy of this licence, visit http://creativecommons.org/licenses/by/4.0/.

\section{References}

1. Mornet E (2007) Hypophosphatasia. Orphanet J Rare Dis 2:40

2. Whyte MP (2010) Physiological role of alkaline phosphatase explored in hypophosphatasia. Ann N Y Acad Sci 1192:190-200

3. Mornet E (2008) Hypophosphatasia. Best Pract Res Clin Rheumatol 22:113-127

4. Baumgartner-Sigl S, Haberlandt E, Mumm S, Scholl-Burgi S, Sergi C, Ryan L, Ericson KL, Whyte MP, Hogler W (2007) Pyridoxine-responsive seizures as the first symptom of infantile hypophosphatasia caused by two novel missense mutations (c.677T\%3eC, p. M226T; c.1112C\%3eT, p.T371I) of the tissuenonspecific alkaline phosphatase gene. Bone 40:1655-1661

5. Ozono K, Michigami T (1559delT) Hypophosphatasia now draws more attention of both clinicians and researchers: a commentary on Prevalence of c. 1559delT in ALPL, a common mutation resulting in the perinatal (lethal) form of hypophosphatasias in Japanese and effects of the mutation on heterozygous carriers. J Hum Genet 56:174-176

6. Wenkert D, McAlister WH, Coburn SP, Zerega JA, Ryan LM, Ericson KL, Hersh JH, Mumm S, Whyte MP (2011) Hypophosphatasia: nonlethal disease despite skeletal presentation in utero (17 new cases and literature review). J Bone Miner Res 26:2389-2398

7. Michigami T, Uchihashi T, Suzuki A, Tachikawa K, Nakajima S, Ozono K (2005) Common mutations F310L and T1559del in the tissue-nonspecific alkaline phosphatase gene are related to distinct phenotypes in Japanese patients with hypophosphatasia. Eur J Pediatr 164:277-282

8. Whyte MP, Zhang F, Wenkert D, McAlister WH, Mack KE, Benigno MC, Coburn SP, Wagy S, Griffin DM, Ericson KL, Mumm S (2015) Hypophosphatasia: validation and expansion of the clinical nosology for children from 25 years experience with 173 pediatric patients. Bone 75:229-239

9. Whyte MP, Valdes R Jr, Ryan LM, McAlister WH (1982) Infantile hypophosphatasia: enzyme replacement therapy by intravenous infusion of alkaline phosphatase-rich plasma from patients with Paget bone disease. J Pediatr 101:379-386

10. Millan JL, Narisawa S, Lemire I, Loisel TP, Boileau G, Leonard P, Gramatikova S, Terkeltaub R, Camacho NP, McKee MD, Crine P, Whyte MP (2008) Enzyme replacement therapy for murine hypophosphatasia. J Bone Miner Res 23:777-787

11. Low MG, Saltiel AR (1988) Structural and functional roles of glycosyl-phosphatidylinositol in membranes. Science 239:268-275

12. Whyte MP, Greenberg CR, Salman NJ, Bober MB, McAlister WH, Wenkert D, Van Sickle BJ, Simmons JH, Edgar TS, Bauer ML, Hamdan MA, Bishop N, Lutz RE, McGinn M, Craig S, Moore JN, Taylor JW, Cleveland RH, Cranley WR, Lim R, Thacher TD, Mayhew JE, Downs M, Millan JL, Skrinar AM, Crine P, Landy H (2012) Enzyme-replacement therapy in lifethreatening hypophosphatasia. N Engl J Med 366:904-913

13. Aggarwal SR (2014) A survey of breakthrough therapy designations. Nat Biotechnol 32:323-330

14. Okazaki Y, Kitajima H, Mochizuki N, Kitaoka T, Michigami T, Ozono K (2016) Lethal hypophosphatasia successfully treated with enzyme replacement from day 1 after birth. Eur J Pediatr 175:433-437

15. Whyte MP, Rockman-Greenberg C, Ozono K, Riese R, Moseley S, Melian A, Thompson DD, Bishop N, Hofmann C (2016) Asfotase Alfa treatment improves survival for perinatal and infantile hypophosphatasia. J Clin Endocrinol Metab 101:334-342

16. Choida V, Bubbear JS (2019) Update on the management of hypophosphatasia. Therap Adv Musculoskelet Dis 11:1759720x19863997 
17. Narisawa S, Frohlander N, Millan JL (1997) Inactivation of two mouse alkaline phosphatase genes and establishment of a model of infantile hypophosphatasia. Dev Dyn 208:432-446

18. Nakano C, Kitabatake Y, Takeyari S, Ohata Y, Kubota T, Taketani K, Kogo M, Ozono K (2019) Genetic correction of induced pluripotent stem cells mediated by transcription activator-like effector nucleases targeting ALPL recovers enzyme activity and calcification in vitro. Mol Genet Metab 127:158-165

19. Matsumoto T, Miyake K, Yamamoto S, Orimo H, Miyake N, Odagaki Y, Adachi K, Iijima O, Narisawa S, Millan JL, Fukunaga Y, Shimada T (2011) Rescue of severe infantile hypophosphatasia mice by AAV-mediated sustained expression of soluble alkaline phosphatase. Hum Gene Ther 22:1355-1364

20. Nakamura-Takahashi A, Miyake K, Watanabe A, Hirai Y, Iijima O, Miyake N, Adachi K, Nitahara-Kasahara Y, Kinoshita H, Noguchi T, Abe S, Narisawa S, Millan JL, Shimada T, Okada T (2016) Treatment of hypophosphatasia by muscle-directed expression of bone-targeted alkaline phosphatase via self-complementary AAV8 vector. Mol Ther Methods Clin Dev 3:15059

21. Miyake K, Miyake N, Yamazaki Y, Shimada T, Hirai Y (2012) Serotype-independent method of recombinant adeno-associated virus (AAV) vector production and purification. J Nippon Med School 79:394-402

22. Negyessy L, Xiao J, Kantor O, Kovacs GG, Palkovits M, Doczi TP, Renaud L, Baksa G, Glasz T, Ashaber M, Barone P, Fonta C (2011) Layer-specific activity of tissue non-specific alkaline phosphatase in the human neocortex. Neuroscience 172:406-418

23. Sogabe N, Oda K, Nakamura H, Orimo H, Watanabe H, Hosoi T, Goseki-Sone M (2008) Molecular effects of the tissue-nonspecific alkaline phosphatase gene polymorphism (787T \%3e C) associated with bone mineral density. Biomed Res (Tokyo, Japan) 29:213-219

24. Bouxsein ML, Boyd SK, Christiansen BA, Guldberg RE, Jepsen KJ, Muller R (2010) Guidelines for assessment of bone microstructure in rodents using micro-computed tomography. J Bone Miner Res 25:1468-1486

25. Noguchi T, Matsunaga S, Kinoshita H, Fukuda M, Saka H, Ide Y, Abe S (2013) A site-specific comparison of the trabecular structure in senescence-accelerated mice-evaluation of time-course changes in bone architecture using in vivo micro-CT. J Hard Tissue Biol 22:171-176

26. Kawamoto T, Kawamoto K (2014) Preparation of thin frozen sections from nonfixed and undecalcified hard tissues using Kawamot's film method (2012). Methods Mol Biol (Clifton, N.J.) 1130:149-164

27. Carter DR, Hayes WC (1977) The compressive behavior of bone as a two-phase porous structure. J Bone Joint Surg Am 59:954-962

28. Pistoia W, van Rietbergen B, Lochmuller EM, Lill CA, Eckstein F, Ruegsegger P (2002) Estimation of distal radius failure load with micro-finite element analysis models based on three-dimensional peripheral quantitative computed tomography images. Bone 30:842-848

29. Takao-Kawabata R, Isogai Y, Takakura A, Shimazu Y, Sugimoto E, Nakazono O, Ikegaki I, Kuriyama H, Tanaka S, Oda H, Ishizuya T (2015) Three-times-weekly administration of teriparatide improves vertebral and peripheral bone density, microarchitecture, and mechanical properties without accelerating bone resorption in ovariectomized rats. Calcif Tissue Int 97:156-168

30. Kurokawa K, Shibasaki M, Mizuno K, Ohkuma S (2011) Gabapentin blocks methamphetamine-induced sensitization and conditioned place preference via inhibition of alpha(2)/delta-1 subunits of the voltage-gated calcium channels. Neuroscience 176:328-335
31. Yamamoto $\mathrm{S}$, Orimo $\mathrm{H}$, Matsumoto T, Iijima O, Narisawa $\mathrm{S}$, Maeda T, Millan JL, Shimada T (2011) Prolonged survival and phenotypic correction of Akp2(-/-) hypophosphatasia mice by lentiviral gene therapy. J Bone Miner Res 26:135-142

32. Bullinger M, Bloemeke J, Mericq V, Sommer R, Gaete X, Ross JL, Yu YM, Permuy J, Gagliardi P, Damaso YL, Mauras N (2018) Quality of life in adolescent boys with idiopathic short stature: positive impact of growth hormone and aromatase inhibitors. Horm Res Paediatr 90:381-392

33. Gonzalez Briceno LG, Viaud M, Beltrand J, Flechtner I, Dassa Y, Samara-Boustani D, Thalassinos C, Pauwels C, Busiah K, Pinto G, Jaquet D, Polak M (2019) Improved general and height-specific quality of life in children with short stature after 1 year on growth hormone. J Clin Endocrinol Metab 104:2103-2111

34. Seikaly MG, Kopanati S, Salhab N, Waber P, Patterson D, Browne R, Herring JA (2005) Impact of alendronate on quality of life in children with osteogenesis imperfecta. J Pediatr Orthop 25:786-791

35. Nathwani AC, Tuddenham EG, Rangarajan S, Rosales C, McIntosh J, Linch DC, Chowdary P, Riddell A, Pie AJ, Harrington C, O’Beirne J, Smith K, Pasi J, Glader B, Rustagi P, Ng CY, Kay MA, Zhou J, Spence Y, Morton CL, Allay J, Coleman J, Sleep S, Cunningham JM, Srivastava D, Basner-Tschakarjan E, Mingozzi F, High KA, Gray JT, Reiss UM, Nienhuis AW, Davidoff AM (2011) Adenovirus-associated virus vector-mediated gene transfer in hemophilia B. N Engl J Med 365:2357-2365

36. Oikawa H, Tomatsu S, Haupt B, Montano AM, Shimada T, Sly WS (2014) Enzyme replacement therapy on hypophosphatasia mouse model. J Inherit Metab Dis 37:309-317

37. Qian N, Ichimura A, Takei D, Sakaguchi R, Kitani A, Nagaoka R, Tomizawa M, Miyazaki Y, Miyachi H, Numata T, Kakizawa S, Nishi M, Mori Y, Takeshima H (2019) TRPM7 channels mediate spontaneous $\mathrm{Ca}(2+)$ fluctuations in growth plate chondrocytes that promote bone development. Sci Signal 12:eaaw4847

38. Hinderer C, Katz N, Buza EL, Dyer C, Goode T, Bell P, Richman LK, Wilson JM (2018) Severe toxicity in nonhuman primates and piglets following high-dose intravenous administration of an adeno-associated virus vector expressing human SMN. Hum Gene Ther 29:285-298

39. Xiong W, Wu DM, Xue Y, Wang SK, Chung MJ, Ji X, Rana P, Zhao SR, Mai S, Cepko CL (2019) AAV cis-regulatory sequences are correlated with ocular toxicity. Proc Natl Acad Sci USA 116:5785-5794

40. Lock M, Alvira MR, Wilson JM (2012) Analysis of particle content of recombinant adeno-associated virus serotype $8 \mathrm{vec}$ tors by ion-exchange chromatography. Hum Gene Ther Methods 23:56-64

41. Hordeaux J, Hinderer C, Goode T, Katz N, Buza EL, Bell P, Calcedo R, Richman LK, Wilson JM (2018) Toxicology study of intra-cisterna magna adeno-associated virus 9 expressing human alpha-L-iduronidase in rhesus macaques. Mol Ther Methods Clin Dev 10:79-88

42. Sugano H, Matsumoto $\mathrm{T}$, Miyake $\mathrm{K}$, Watanabe A, Iijima O, Migita M, Narisawa S, Millan JL, Fukunaga Y, Shimada T (2012) Successful gene therapy in utero for lethal murine hypophosphatasia. Hum Gene Ther 23:399-406

43. Seshia SS, Derbyshire G, Haworth JC, Hoogstraten J (1990) Myopathy with hypophosphatasia. Arch Dis Child 65:130-131 
44. Beck C, Morbach H, Wirth C, Beer M, Girschick HJ (2011) Whole-body MRI in the childhood form of hypophosphatasia. Rheumatol Int 31:1315-1320

45. Williams DK, Pinzon C, Huggins S, Pryor JH, Falck A, Herman F, Oldeschulte J, Chavez MB, Foster BL, White SH, Westhusin ME, Suva LJ, Long CR, Gaddy D (2018) Genetic engineering a large animal model of human hypophosphatasia in sheep. Sci Rep $8: 16945$
46. Silva I, Castelao W, Mateus M, Branco JC (2012) Childhood hypophosphatasia with myopathy: clinical report with recent update. Acta Reumatol Port 37:92-96

Publisher's Note Springer Nature remains neutral with regard to jurisdictional claims in published maps and institutional affiliations. 